\title{
Synthesis and Characterization of Rare Earth Ion Doped Nano ZnO
}

\author{
Rita John ${ }^{1, *}, \quad$ Rajaram Rajakumari ${ }^{2}$
}

(Received 19 March 2012; accepted 2 May 2012; published online 28 June 2012.)

\begin{abstract}
Zinc oxide $(\mathrm{ZnO})$ doped with erbium at different concentrations was synthesized by solid-state reaction method and characterized by X-ray diffraction (XRD), scanning electron microscopic (SEM), UVabsorption spectroscopy, photoluminescence (PL) study and vibrating sample magnetometer. The XRD studies exhibit the presence of wurtzite crystal structure similar to the parent compound $\mathrm{ZnO}$ in $1 \% \mathrm{Er}^{3+}$ doped $\mathrm{ZnO}$, suggesting that doped $\mathrm{Er}^{3+}$ ions sit at the regular $\mathrm{Zn}^{2+}$ sites. However, same studies spread over the samples with $\mathrm{Er}^{3+}$ content $>1 \%$ reveals the occurrence of secondary phase. SEM images of $1 \% \mathrm{Er}^{3+}$ doped $\mathrm{ZnO}$ show the polycrystalline nature of the synthesized sample. UV-visible absorption spectrum of $\mathrm{Er}^{3+}$ doped $\mathrm{ZnO}$ nanocrystals shows a strong absorption peak at $388 \mathrm{~nm}$ due to $\mathrm{ZnO}$ band to band transition. The PL study exhibits emission in the visible region, due to excitonic as well as defect related transitions. The magnetizationfield curve of $\mathrm{Er}^{3+}$ doped $\mathrm{ZnO}$ nanocrystals showed ferromagnetic property at room-temperature.
\end{abstract}

Keywords: Erbium doped zinc oxide; Solid state reaction; X-ray diffraction; Photoluminescence; VSM; Room-temperature ferromagnetism

Citation: Rita John and Rajaram Rajakumari, "Synthesis and Characterization of Rare Earth Ion Doped Nano ZnO", Nano-Micro Lett. 4 (2), 65-72 (2012). http://dx.doi.org/10.3786/nml.v4i2.p65-72

\section{Introduction}

The promise of nanocrystals as a technological material for applications including wavelength tunable lasers [1], bioimaging [2], and solar cells [3] may ultimately depend on tailoring their behavior by adding impurities through doping. Impurities are reported to modify electronic, optical, and magnetic properties of bulk semiconductors. Dopants can strongly influence optical behavior. Although undoped nanocrystals are highly fluorescent with a color that depends on size, lasers based on this emission are intrinsically inefficient. Several approaches can improve this situation [1], and one possibility is to incorporate dopants that provide carriers. Dopants in nanocrystals lead to phenomena not found in the bulk because their electronic states are confined to a small volume. For example, n- or p-type dopants can auto-ionize without thermal activation. This occurs because a carrier inside the crystalline occupy one of the confined electronic states, which increase in energy with decreasing nanocrystal size [4]. Below a critical radius, the confinement energy exceeds the Coulomb interaction between the ionized impurity and the carrier [5], which then automatically occupies a nanocrystal state.

The critical role that dopants play in semiconductor devices has stimulated research on the properties and the potential applications of semiconductor nanocrystals [4]. Semiconductors doped with rare earth ions are excellent phosphors of high efficiency and low degradation in addition to their unique physical and chemical properties [6]. II-VI compound semiconductors have been found to be unique host materials for doping of optically active impurities which exhibit luminescence at room temperature [7]. ZnO, an II-VI compound semiconductor with a wide band gap of about $3.4 \mathrm{eV}$, is an attractive material for applications in optical devices such as blue-, violet-, and UV-light emitting diodes (LEDs) and laser diodes (LDs). We have reported

\footnotetext{
${ }^{1}$ Department of Theoretical Physics, University of Madras, Guindy Campus, Chennai-600 025, India

${ }^{2}$ Department of Physics, Queen Mary's College, Chennai-600 005, India

*Corresponding author. E-mail: john_abraham@sify.com
} 
quantum confinement, influence of surfactant and temperature on the morphology of nano $\mathrm{ZnO}$ [8]. In the present paper, we report the influence of rare earth element erbium as dopant in $\mathrm{ZnO}$.

The rare earth ion doped $\mathrm{ZnO}$ has the potential to be a highly multifunctional material with coexisting semiconducting, electromechanical and optical properties. The rare earth ions are better luminescent materials because of the sharp and intense emission due to their If intra shell transitions. Elements of the lanthanide series are characterized by a partially filled $4 \mathrm{f}$ energy level, surrounded by full $5 \mathrm{~s}$ and $5 \mathrm{p}$ orbitals. Shielding effects of the $5 \mathrm{~s}$ and $5 \mathrm{p}$ orbitals allow the Photoluminescence (PL) spectra of rare-earth ions to show emission frequencies, which are relatively host independent [9]. Among the lanthanides, erbium has attracted significant attention due to its enormous potential in various applications. The telecommunications industry has taken advantage of the PL characteristics of $\mathrm{Er}^{3+}$ doped optical amplifiers for application in high bandwidth data transmission lines [10, 11]. Although there are a few reports in literature on rare earth doped compounds, as bulk and nanostructures [12-16], their structural and luminescence properties are not very clear due to the difficulties in doping procedures. Further optimization of the procedures is needed for the development of complete understanding of doping processes. Present work is one such attempt in this direction. In this work, we are successful in doping erbium in $\mathrm{ZnO}$, which showed improved luminescence characteristics. Compared to the conventional methods, the solid-state reaction has advantage of its low cost, high yield, and ability to achieve high purity in making oxide nano powders [17].

\section{Experimental}

$\mathrm{ZnO}$ nanopowder doped with erbium was prepared by solid-state reaction method to study their structural and optical properties. The chemicals used in the experiment are $\mathrm{ZnO}$ (99.9\% pure), $\mathrm{Er}_{2} \mathrm{O}_{3}$ (99.9\% pure) and $\mathrm{LiOH}_{\mathrm{H}} \mathrm{H}_{2} \mathrm{O}$ (99.9\% pure) brought from Merck company. The samples were prepared by thoroughly mixing $\mathrm{Er}_{2} \mathrm{O}_{3}$ and $\mathrm{ZnO}$ powders. Slurry was made with Lithium hydroxide $(\mathrm{LiOH})$ solution and ethanol in a beaker and dried in an oven. $\mathrm{LiOH}$ is an inorganic and water soluble compound. In the present study, $\mathrm{LiOH}$ was used as a heat transfer medium, when $\mathrm{ZnO}$ doped with erbium. After drying, the mixture was ground for $45 \mathrm{~min}$ and sintered in air at $900^{\circ} \mathrm{C}$. Samples were made in batches of approximately $5 \mathrm{~g}$ for different concentrations of erbium $(1 \%, 2 \%, 4 \%, 6 \%, 8 \%$, and $10 \%$ ) (Table $1)$.

Table 1 Samples of $\mathrm{ZnO}$ doped with different concentrations of erbium

\begin{tabular}{ccccccc}
\hline $\begin{array}{c}\text { Sample } \\
(\%, \mathrm{Er} \\
\text { doped } \\
\mathrm{ZnO})\end{array}$ & $\begin{array}{c}\mathrm{ZnO} \\
(\%)\end{array}$ & $\begin{array}{c}\mathrm{Er} \\
(\%)\end{array}$ & $\begin{array}{c}\mathrm{Li} \\
(\%)\end{array}$ & $\begin{array}{c}\text { Temp. } \\
\left({ }^{\circ} \mathrm{C}\right)\end{array}$ & Ambiance & $\begin{array}{c}\text { Total } \\
\text { weight } \\
\text { of the } \\
\text { sample } \\
(\mathrm{g})\end{array}$ \\
\hline 1 & 98.7 & 1 & 0.3 & 900 & Air & 5 \\
2 & 97.7 & 2 & 0.3 & 900 & Air & 5 \\
4 & 95.7 & 4 & 0.3 & 900 & Air & 5 \\
6 & 93.7 & 6 & 0.3 & 900 & Air & 5 \\
8 & 91.7 & 8 & 0.3 & 900 & Air & 5 \\
10 & 89.7 & 10 & 0.3 & 900 & Air & 5 \\
\hline
\end{tabular}

Measurements for all the samples were carried out at the same time and in the same setting of the instrument. The crystal structure of the synthesized sample was studied by using X-ray diffractometer (XRD) employing $\mathrm{Cu}-\mathrm{K} \alpha$ radiation. The surface morphology and the grain size were estimated by employing a scanning electron microscope (SEM). PL excitation spectroscopy was done using Perkin Elmer spectrometer to study the available energy states and allowed transition between states. The magnetic hysteresis (M-H) loop was measured by using vibrating sample magnetometer (VSM).

\section{Results and Discussion}

\section{Determination of lattice parameters from XRD}

The XRD pattern of undoped and $1 \%$ erbium doped $\mathrm{ZnO}$ is shown in Fig. 1. The analysis of the diffraction peaks of both undoped and $1 \%$ erbium doped $\mathrm{ZnO}$, revealed the presence of hexagonal wurtzite structure of bulk $\mathrm{ZnO}$ with lattice constants $a=b=2.8348 \AA$, $c=5.2478 \AA$ and $a=b=2.8366 \AA, c=5.2492 \AA$, respectively. Diffraction peaks corresponding to reflections peaks of (100), (002), (101), (102), (110), (103),

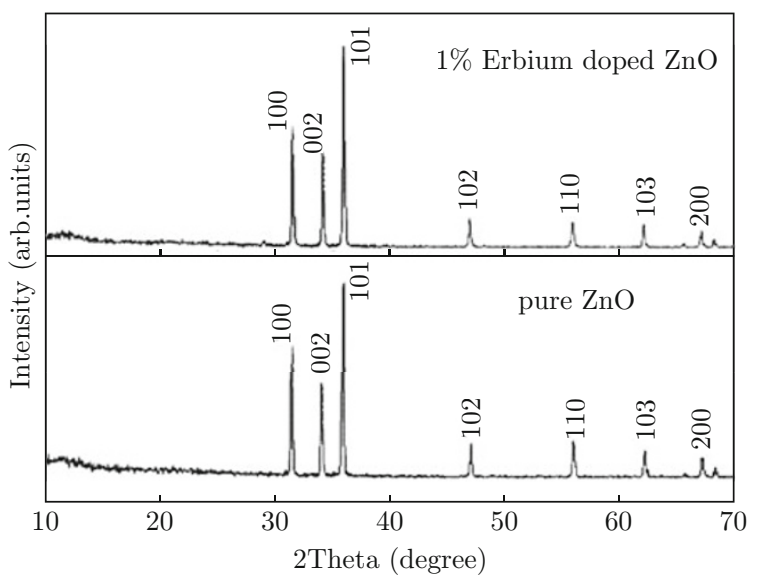

Fig. 1 XRD patterns recorded from undoped and $1 \% \mathrm{Er}^{3+}$ doped $\mathrm{ZnO}$.

(200) crystal planes, which are consistent with standard JCPDS data of $\mathrm{ZnO}$ (Card No. 89-1397). It is suggested 
that the wurtzite structure is unchanged when the concentration of erbium in $\mathrm{ZnO}$ is minimum.

The XRD peaks of the increasing concentration $(4 \%$, $6 \%, 8 \%$, and $10 \%$ ) of erbium in $\mathrm{ZnO}$ showed the presence of extra phase related to $\mathrm{Er}_{2} \mathrm{O}_{3}$ in addition to the wurtzite phase of $\mathrm{ZnO}$ (Fig. 2). The peaks in the diffraction pattern of doped samples are slightly shifted as compared to undoped $\mathrm{ZnO}$. This shows that small variation in the lattice parameters occurs as the $\mathrm{Er}^{3+}$ concentration increases. The nanocrystals exhibited changes in relative intensities and crystallite size with changes in the doping concentration of erbium. The difference in band gap between the bulk and nanocrystals, calculated using the formula $\Delta E_{g}=E_{g}^{n}-E_{g}^{b}=$ $h^{2} / 8 a^{2}\left(1 / m_{e}+1 / m_{h}\right)$, was found to increase slightly from $5.71 \times 10^{-4} \mathrm{eV}$ to $6.93 \times 10^{-4} \mathrm{eV}$ as the concentration of erbium in $\mathrm{ZnO}$ was increased (Table 2). The $c / a$ ratio of $\mathrm{Er}^{3+}$ doped $\mathrm{ZnO}$ increased from1.60 to 1.62 and the cell volume was found to increase from 23.749

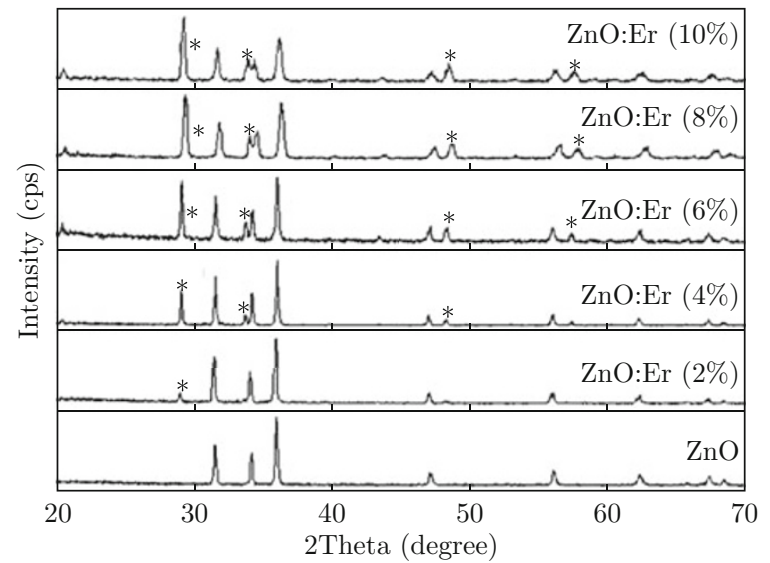

Fig. 2 XRD pattern of undoped and $\mathrm{Er}^{3+}$ doped $\mathrm{ZnO}$ at different concentrations. Peaks corresponding to secondary phase appearing in the samples with $\mathrm{Er}^{3+}$ content $>1 \%$ has been marked by "**.

$\AA^{3}$ to $24.706 \AA^{3}$ (Table 2) as the concentration of erbium increased. The anion-cation bond length or the nearest neighbor distance was calculated to be 0.376 for all the concentrations of erbium in $\mathrm{ZnO}$ (Table 2). The iconicity of oxygen has played a major role in bonding, where the depleted $d$ electrons of $\mathrm{Zn}$ would have formed a charge cloud around oxygen in bond formation. Hence, $\mathrm{Er}^{3+}$ doping has not influenced the nature of bonding, which is predominantly ionic in nature.

\section{Determination of dislocation density from XRD}

In materials science, dislocation is a crystallographic defect or irregularity within a crystal structure. The presence of dislocations strongly influences many of the properties of materials. Crystalline solids exhibit a periodic crystal structure. The positions of atoms or molecules occur on repeating fixed distances, determined by the unit cell parameters. However, the arrangement of atom or molecules in most crystalline materials is not perfect. The regular patterns are interrupted by crystallographic defects. The movement of dislocation is impeded by other dislocations present in the sample. Thus, a larger dislocation density implies a higher hardness. It is also known that above a certain grain size limit $(\sim 20 \mathrm{~nm})$ the strength of materials increases with decreasing grain size.

The dislocation density $(\delta)$ in the sample was determined using expression,

$$
\delta=15 \beta \cos \theta / 4 a D
$$

where $\delta$ is dislocation density, $\beta$ is broadening of diffraction line measured at half of its maximum intensity (in radian), $\theta$ is Bragg's diffraction angle (in degree), $a$ is lattice constant (in $\mathrm{nm}$ ) and $D$ is particle size (in $\mathrm{nm}$ ). The dislocation density $(\delta)$ was found to increase from $0.33 \times 10^{15} \mathrm{~m}^{-2}$ to $0.36 \times 10^{15} \mathrm{~m}^{-2}$ for $4 \%$ to $8 \%$ erbium doped $\mathrm{ZnO}$ in the (100), (002) and (101) orientations. This value increases to $0.5 \times 10^{15} \mathrm{~m}^{-2}$ to $0.6 \times 10^{15} \mathrm{~m}^{-2}$ when the concentration is increased to $10 \%$ (Table 3 ).

Table 2 Crystalline size and difference in band gap between nano and bulk and lattice parameters of Er doped $\mathrm{ZnO}$

\begin{tabular}{|c|c|c|c|c|c|c|c|}
\hline \multirow{2}{*}{$\begin{array}{l}\text { Concentration of } \\
\text { erbium (\%) }\end{array}$} & \multirow{2}{*}{$\begin{array}{l}\text { Average } \\
\text { crystalline } \\
\text { size }(\mathrm{nm})\end{array}$} & \multirow{2}{*}{$\begin{array}{c}\text { Difference } \\
\text { in band gap } \\
\left(\Delta E_{g}, \mathrm{eV}\right)\end{array}$} & \multicolumn{2}{|c|}{ Lattice constants } & \multirow{2}{*}{$c / a$} & \multirow{2}{*}{$\begin{array}{c}\text { Cell } \\
\text { volume } \\
\left(\stackrel{\circ}{ }^{3}\right)\end{array}$} & \multirow{2}{*}{$\begin{array}{c}\text { Anion-catior } \\
\text { bond length } \\
(\mu)\end{array}$} \\
\hline & & & $a(\AA)$ & $a(\AA)$ & & & \\
\hline 4 & 65 & 0.0005711 & 3.2604 & 5.2232 & 1.602 & 23.749 & 0.37988 \\
\hline 6 & 63 & 0.0006076 & 3.2660 & 5.232 & 1.602 & 23.873 & 0.37988 \\
\hline 8 & 62 & 0.0006274 & 3.2605 & 5.232 & 1.605 & 24.707 & 0.40800 \\
\hline 10 & 59 & 0.0006928 & 3.2600 & 5.296 & 1.625 & 24.746 & 0.37630 \\
\hline
\end{tabular}


Table 3 Dislocation density and specific surface area of $\mathrm{Er}$ doped $\mathrm{ZnO}$

\begin{tabular}{ccccc}
\hline \multirow{2}{*}{$\begin{array}{c}\text { Concentration } \\
\text { of Erbium (\%) }\end{array}$} & \multicolumn{2}{c}{ Dislocation Density $\left(\times 10^{15} \mathrm{~m}^{-2}\right)$} & \begin{tabular}{c} 
Specific \\
surface \\
area \\
\cline { 2 - 4 }$\left(\mathrm{m}^{2} / \mathrm{g}\right)$
\end{tabular} \\
\hline 4 & 0.3359 & 0.3607 & 0.3717 & 16.465 \\
6 & 0.3353 & 0.3601 & 0.3710 & 16.988 \\
8 & 0.3358 & 0.3564 & 0.3614 & 17.262 \\
10 & 0.5943 & 0.3562 & 0.6670 & 18.140 \\
\hline
\end{tabular}

Determination of specific surface area from XRD

Specific surface area is a material property of solids which measures the total surface area per unit of mass, solid or bulk volume, or cross-sectional area. It is a derived scientific value that can be used to determine the type and properties of a material. It has a particular importance for adsorption, heterogeneous catalysis, and reactions on surfaces. Specific surface area of the material can be determined using the expression,

$$
S=6 \times 10^{3} / D_{p} \cdot \rho
$$

where $S$ is the specific surface area, $D_{p}$ is the size of the particle and $\rho$ is the density of $\mathrm{ZnO} 5.606 \mathrm{~g} / \mathrm{cm}^{3}$. The specific surface area $(S)$ of erbium doped $\mathrm{ZnO}$ nanocrystals was found to increase from $16.47 \mathrm{~m}^{2} \cdot \mathrm{g}^{-1}$
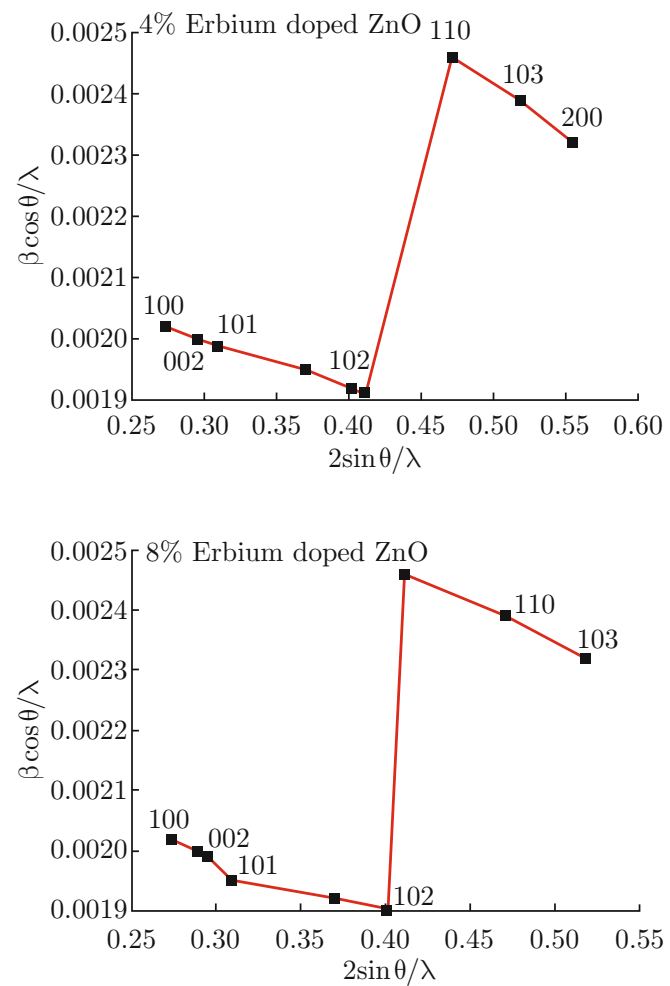

to $18.10 \mathrm{~m}^{2} \cdot \mathrm{g}^{-1}$ as the concentration of erbium in $\mathrm{ZnO}$ increased from $4 \%$ to $10 \%$ (Table 3 ).

\section{X-ray line broadening-Williamson-Hall Tech- nique}

Williamson and Hall (W-H) plot is a classical method to obtain qualitative information of anisotropy in broadening peaks. Williamson and Hall [18] assumed that both size and strain broadened profiles are Lorentzian. Based on this assumption, a mathematical relation was established between the integral breadth $(\beta)$, volume weighted average domain size $\left(D_{v}\right)$ and the microstrain $(\varepsilon)$ as follows:

$$
\beta \cos \theta / \lambda=1 / D_{v}+2 \varepsilon(2 \sin \theta / \lambda)
$$

The plot of $(\beta \cos \theta / \lambda)$ versus $(2 \sin \theta / \lambda)$ gives the value of the microstrain from the slope and domain size from the ordinate intercept. If the points in the $\mathrm{W}-\mathrm{H}$ plot are scattered, i.e., if $(\beta \cos \theta / \lambda)$ is not a monotonous function of $(2 \sin \theta / \lambda)$, the broadening is termed as anisotropic. The $\mathrm{W}-\mathrm{H}$ plot of erbium doped $\mathrm{ZnO}$ is shown in Fig. 3. It is observed that the line broadening is not a monotonous function of the diffraction angle, indicating the anisotropic of the line profile. The strain value extracted from the $\mathrm{W}-\mathrm{H}$ linear fit (Fig. 4) is 0.001 for all the samples.
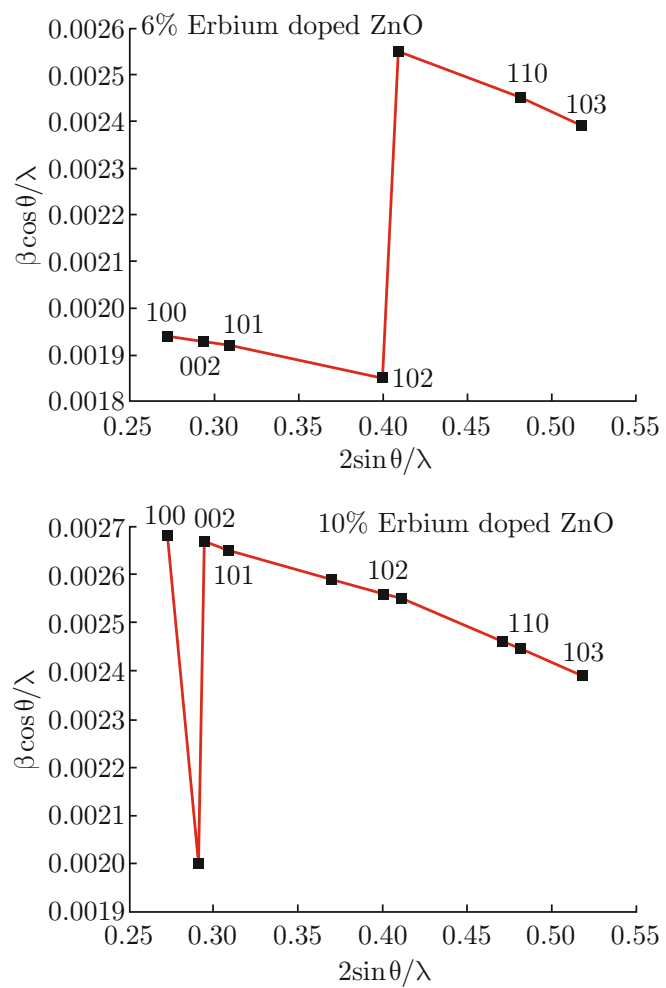

Fig. 3 Williamson-Hall plot for 4\%,6\%, 8\%, and 10\% Erbium doped $\mathrm{ZnO}$ at different deformations. 

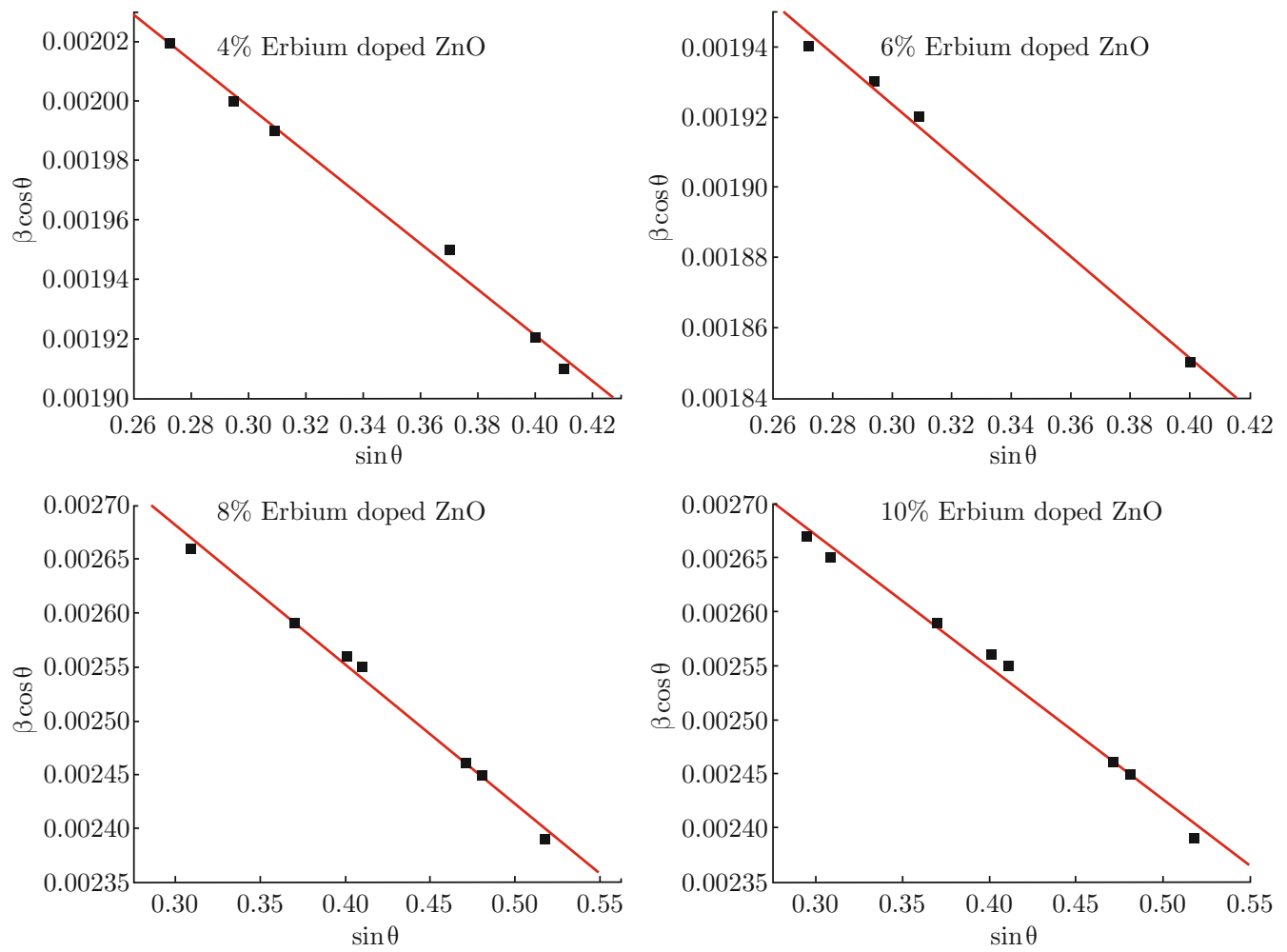

Fig. 4 Williamson-Hall linear fit of 4\%,6\%, 8\%, and 10\% erbium doped $\mathrm{ZnO}$.

\section{Morphological study}

The SEM technique was employed to explore the size and distribution of particles in the materials. The images of $1 \% \mathrm{Er}^{3+}$ doped $\mathrm{ZnO}$ are shown in Fig. 5 . It can be found that the sample synthesized through solid state reaction route crystallites are closely packed and have smaller sizes. The crystallites are nearly spherical shaped. The estimated particle size was $60 \mathrm{~nm}$.

\section{Optical studies}

The interest in erbium doped $\mathrm{ZnO}$ stems from their possible use as fluorescence labels and as phosphor materials. For this the light emission characteristics of the prepared sample was studied using photoluminescence excitation spectroscopy. The PL spectrum of $1 \% \mathrm{Er}^{3+}$ doped $\mathrm{ZnO}$ with $\lambda_{\text {exci }}=528 \mathrm{~nm}$ is shown in Fig. 6 . The PL spectrum exhibits strong near-band-edge emission at $381-394 \mathrm{~nm}$ with a full width at half maximum about $11 \mathrm{~nm}$. The PL peaks from 381 to $394 \mathrm{~nm}$ derive from the quantum size effect. Broad emission peak at $478 \mathrm{~nm}$ can be ascribed to the mediated defect levels in the band gap such as oxygen vacancies which is a native defect of $\mathrm{ZnO}$ [19]. Oxygen vacancy acts as radiative center in luminescence process.

$\mathrm{UV} /$ Visible spectrum of $2 \% \mathrm{Er}^{3+}$ doped $\mathrm{ZnO}$ is shown in Fig. 7. The absorption spectrum of $\mathrm{Er}^{3+}$ doped $\mathrm{ZnO}$ shows pronounced shoulder at $388 \mathrm{~nm}$, corresponding to the energy band gap of $3.2 \mathrm{eV}$. A strong
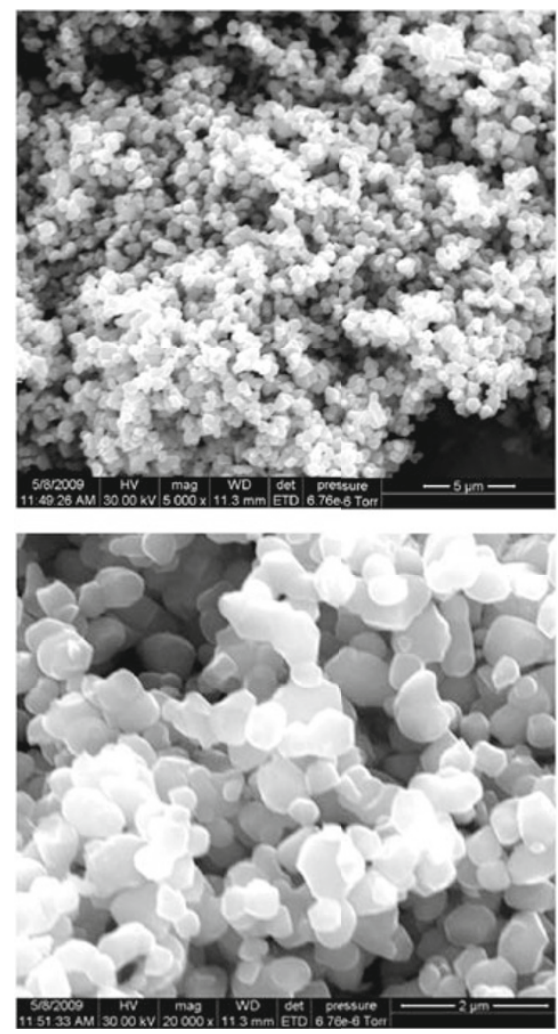

Fig. 5 SEM images of $1 \% \mathrm{Er}^{3+}$ doped $\mathrm{ZnO}$.

UV absorption band at $388 \mathrm{~nm}$ is assigned to the $\mathrm{ZnO}$ band-to-band transition. The decrease in band gap from $3.37 \mathrm{eV}$ (bulk $\mathrm{ZnO}$ ) to $3.2 \mathrm{eV}$ is due to the effect 
of the dopant, behaved as a substitutional impurity located in the lattice position of $\mathrm{ZnO}$.

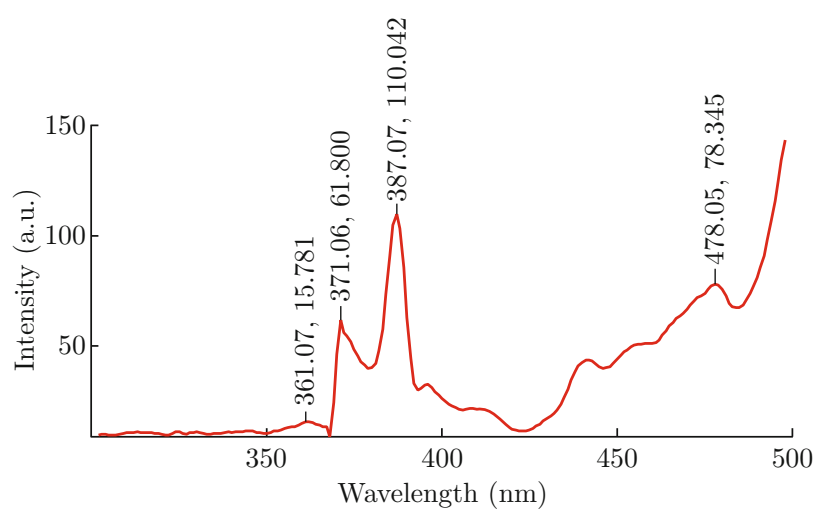

Fig. 6 PL spectrum of $1 \% \mathrm{Er}^{3+}$ doped $\mathrm{ZnO}$.

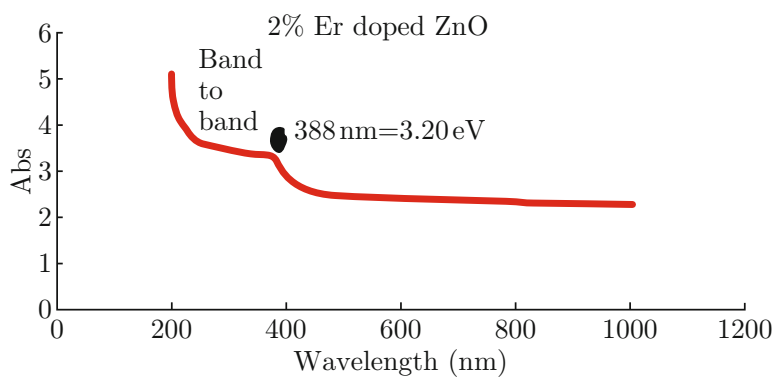

Fig. 7 UV/Visible spectrum of $2 \% \mathrm{Er}^{3+}$ doped $\mathrm{ZnO}$.

\section{Electrical studies}

The variation of resistivity with temperature for undoped $\mathrm{ZnO}$ and $1 \% \mathrm{Er}^{3+}$ doped $\mathrm{ZnO}$ is shown in Fig. 8 . The resistivity measurements were taken from room temperature $(303 \mathrm{~K})$ to $463 \mathrm{~K}$. It is observed that for undoped and $1 \% \mathrm{Er}^{3+}$ doped $\mathrm{ZnO}$, the resistivity decreases as the temperature increases. The variation of resistance with temperature is marked in three regions in the resistivity-temperature plot. Initially the resistivity decreases very sharply from 303-320 K, it is lower in the shallow region from $320-340 \mathrm{~K}$, and steady decrease beyond $345 \mathrm{~K}$ for undoped $\mathrm{ZnO}$. For $1 \% \mathrm{Er}^{3+}$ doped $\mathrm{ZnO}$, the resistivity decreases rapidly from 300$322 \mathrm{~K}$, and it almost reaches a steady state in the range $322-362 \mathrm{~K}$, and a rapid decrease from $362-382 \mathrm{~K}$ and a gradual decrease beyond $382 \mathrm{~K}$ is observed. This analysis indicates the increase in conductivity of both undoped and $1 \% \mathrm{Er}^{3+}$ doped $\mathrm{ZnO}$. This is due to the negative temperature coefficient of resistance of $\mathrm{Er}^{3+}$ doped $\mathrm{ZnO}$ semiconductor, in which the occupancy of the conduction band goes up due to increase in temperature. Thus, $1 \% \mathrm{Er}^{3+}$ doped $\mathrm{ZnO}$ can be used in the temperature range $362-382 \mathrm{~K}$ for rapid current conducting device fabrication.
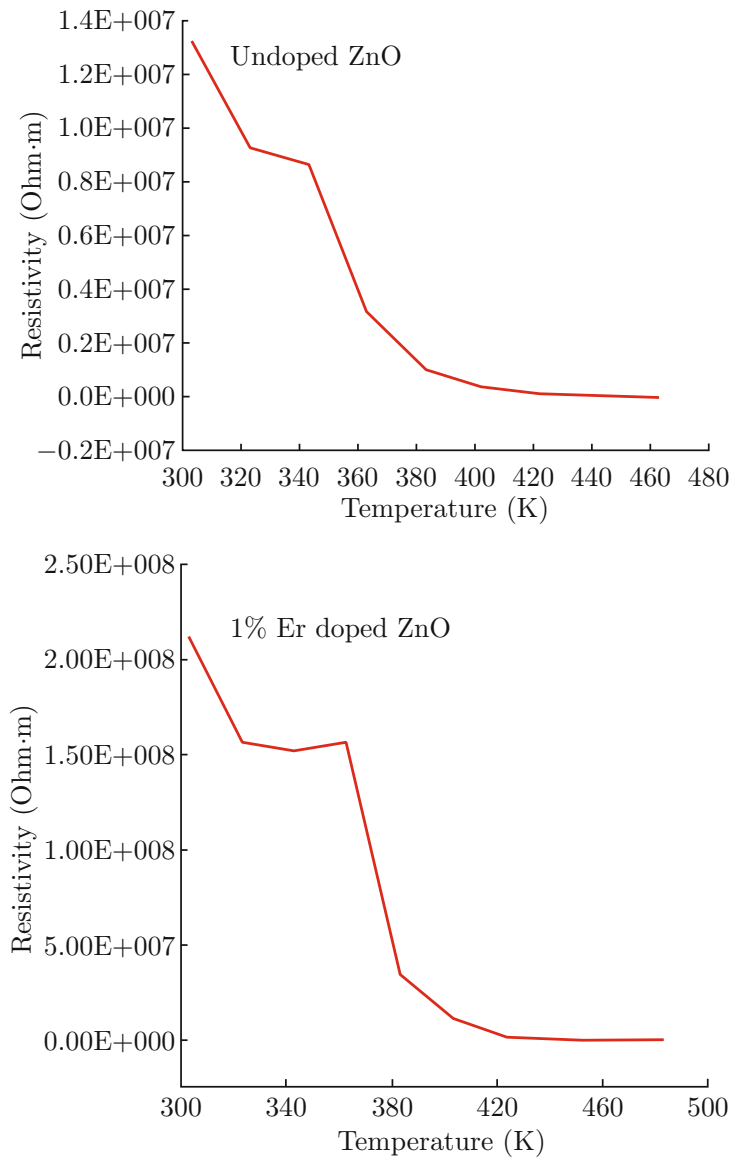

Fig. 8 Resistivity variance with temperature for undoped $1 \%$ Er doped $\mathrm{ZnO}$.

The Arrhenius plots that display the logarithm of kinetic constant (lnK) against inverse temperature of undoped and $1 \% \mathrm{Er}^{3+}$ doped $\mathrm{ZnO}$ is shown in Fig. 9. Arrhenius plots are used to analyze the effect of temperature on the rates of chemical reactions. For a singlyrate limited thermally activated process, an Arrhenius plot gives a straight line, from which the activation energy can be determined. Activation energy can be considered as the height of the potential barrier or energy barrier separating two minima of potential energy of the reactants and products of a reaction. For a chemical reaction to proceed at a reasonable rate there should exit an appreciable number of molecules with energy equal to or greater than the activation energy. The activation energy calculated from Arrhenius plots of undoped $\mathrm{ZnO}$ and $1 \% \mathrm{Er}^{3+}$ doped $\mathrm{ZnO}$, increased from $0.77 \mathrm{eV}$ to $1.16 \mathrm{eV}$. The increase in activation energy in $1 \% \mathrm{Er}^{3+}$ doped $\mathrm{ZnO}$ is due to the increased reaction rate and the effective collision per unit volume between the $\mathrm{ZnO}$ and erbium molecules.

\section{Magnetic study}

The significance of magnetism in non-magnetic materials has been focused extensively [20]. Multiple nanostructures of either organic or inorganic systems have 

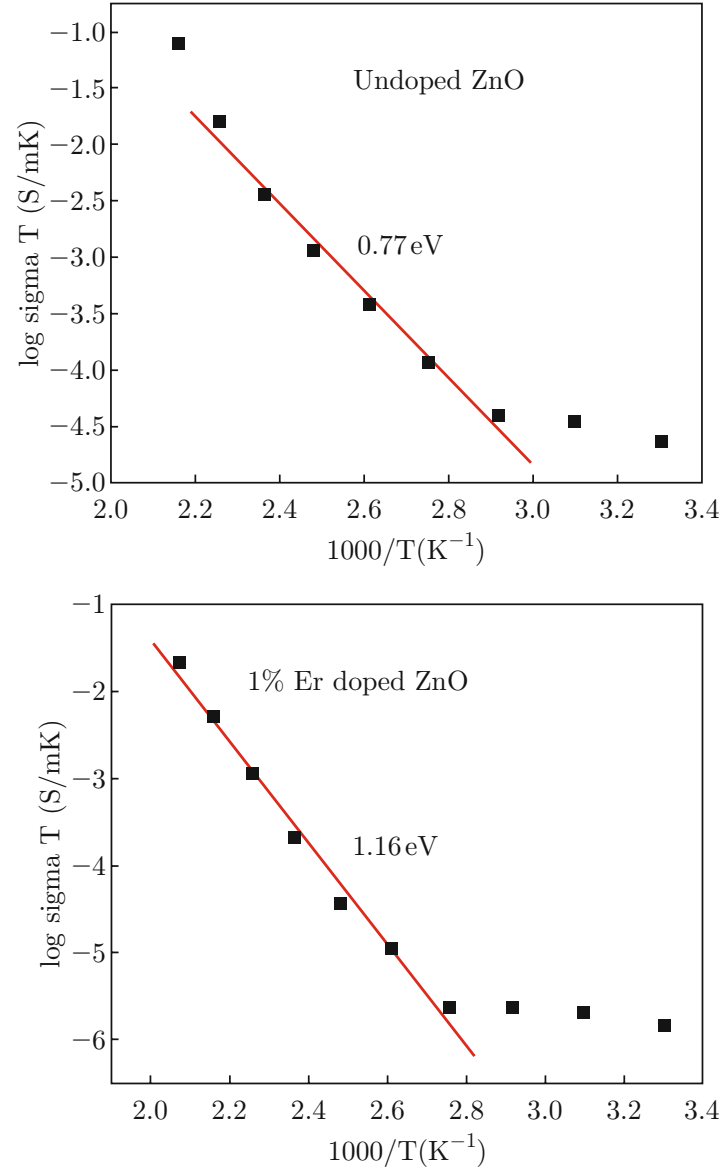

Fig. 9 Arrhenius plot of undoped $\mathrm{ZnO}$ and $1 \% \mathrm{Er}^{3+}$ doped $\mathrm{ZnO}$.

been reported to show magnetic properties in the absence of magnetic elements [21-25], and even the suggestion of magnetism as a universal feature at the nanoscale has been proposed [26]. Sundaresan et al. [27] have shown that nanoparticles of metal oxides of non-magnetic materials, such as $\mathrm{CeO}_{2}, \mathrm{Al}_{2} \mathrm{O}_{3}, \mathrm{ZnO}$, $\mathrm{In}_{2} \mathrm{O}_{3}$ and $\mathrm{SnO}_{2}$, exhibit room-temperature ferromagnetism. The present study focuses on the effect of rare earth ion $\mathrm{Er}^{3+}$ on the magnetic behaviour of $\mathrm{ZnO}$ at room- temperature. Erbium is one of the rare earth ions, which has more than a half-filled 4 f electron shells. Magnetization of $6 \%$ erbium doped $\mathrm{ZnO}$, as a function of magnetic field, measured at room-temperature, using VSM is shown in Fig. 10. The magnetization curve shows hysteresis, indicating a ferromagnetic ordering at room temperature. The coercivity measured from the plot is $386.55 \mathrm{G}(0.038655 \mathrm{~T})$ and the retentivity is $5.2524 \times 10^{-3} \mathrm{emu} / \mathrm{g}(5.2524 \mathrm{~A} / \mathrm{m})$ and the susceptibility calculated from the plot is 0.01237 . The origin of ferromagnetism may be due to the exchange interactions between unpaired electron spins arising from oxygen vacancies at the surface of the nanoparticles. Sundaresan et al. [27] suggested that all metal oxides in nanoparticulate form exhibit room-temperature ferromagnetism. In general, the magnetic semiconducting system can be characterized by delocalized band electrons, which can be described by extended states. The magnetic ion, on the other hand, is characterized by localized 3d or 4f shells. The localized magnetic moments associated with the magnetic ions and their interaction with the host semiconductor determines the magnetic properties. The interaction responsible for the desired magnetic behavior is $\mathrm{s}$, p-f in the case of rare earth magnetic ions. Thus, erbium doped $\mathrm{ZnO}$ is observed to show dilute magnetic semiconducting behavior.

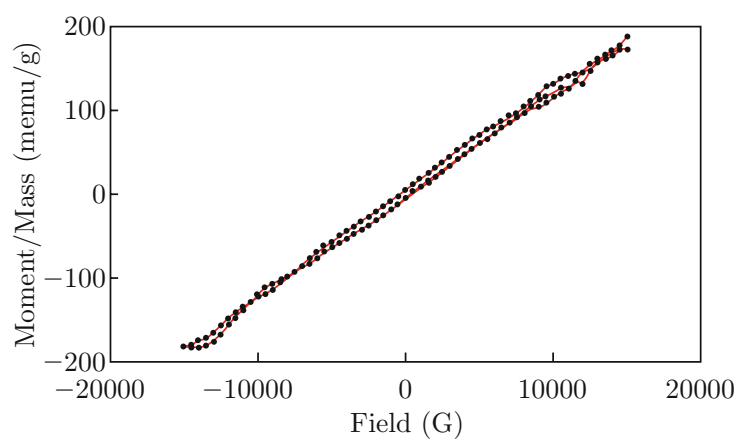

Fig. $10 \mathrm{M}-\mathrm{H}$ curve of $6 \%$ erbium doped $\mathrm{ZnO}$.

\section{Conclusion}

In the present investigation, synthesis of $\mathrm{Er}^{3+}$ doped $\mathrm{ZnO}$ by solid state reaction method seems to be an efficient, inexpensive and easy method. The structural characterization of the sample explored by XRD, shows polycrystalline structure with average crystalline size of $63 \mathrm{~nm}$ and $\mathrm{ZnO}$ has become zinc erbium oxide as the concentration of erbium in $\mathrm{ZnO}$ was increased. W-H plot generated for all the concentrations of erbium in $\mathrm{ZnO}$ showed that the broadening is highly anisotropic. Anisotropic line broadening of erbium doped $\mathrm{ZnO}$ was explained in terms of dislocation induced strain broadening and the dislocation density was found to be of the order of $10^{15} \mathrm{~m}^{-2}$. UV/Visible absorption analysis of $\mathrm{Er}^{3+}$ doped $\mathrm{ZnO}$ reveals the decrease in energy band gap of doped $\mathrm{ZnO}$ nanocrystals and created more defective sites on the $\mathrm{ZnO}$ surface. The increased surface defects are capable of absorbing more visible light. The emission peak at $387 \mathrm{~nm}$ observed from the photoluminescence study shows the improved luminescence characteristics of the $\mathrm{Er}^{3+}$ doped $\mathrm{ZnO}$. Electrical investigation showed an increase in conductivity of undoped and $1 \% \mathrm{Er}^{3+}$ doped $\mathrm{ZnO}$. Activation energy calculated from Arrhenius plot increased for $1 \% \mathrm{Er}^{3+}$ doped $\mathrm{ZnO}$ in comparison with undoped $\mathrm{ZnO}$. The observed hysteresis in the M-H behavior showed the presence of room temperature ferromagnetism (RTFM) in the rare earth ion doped $\mathrm{ZnO}$ nanocrystals. 


\section{References}

[1] V. I. Klimov, S. A. Ivanov, J. Nanda, M. Achermann, I. Bezel, J. A. McGuire and A. Piryatinski, Nature 447, 441 (2007). http://dx.doi.org/10.1038/ nature05839

[2] X. Michalet, F. F. Pinaud, L. A. Bentolila, J. M. Tsay, S. Doose, J. J. Li, G. Sundaresan, A. M. Wu, S. S. Gambhir and S. Weiss, Science 307, 538 (2005). http://dx.doi.org/10.1126/science.1104274

[3] I. Gur, N. A. Fromer, M. L. Geier and A. P. Alivisatos, Science 310, 462 (2005). http://dx.doi. org/10.1126/science. 1117908

[4] P. Alivisatos, Science 271, 933 (1996). http://dx.doi. org/10.1126/science.271.5251.933

[5] A. I. Ekinov, I. A. Kudryavtsev, M. G Ivanor and A. L. Efros, J. Lumi. 46, 83 (1990).

[6] N. Rakov, F. E. Ramos, G. Hirata and M. Xiao, Appl. Phys. Lett. 83, 272 (2003). http://dx.doi.org/10. 1063/1.1592636

[7] H. Ishizumi and Y. Kanemitsu, Appl. Phys. Lett. 86, 253106 (2005). http://dx.doi.org/10.1063/1. 1952576

[8] R. John, F. S. Sasi, R. Rajaram and T. Endo, J. Ceram. Soc. 118, 329 (2010). http://dx.doi.org/10. 2109/jcersj2.118.329

[9] C. Ting, S. Chen, W. Hsich and H. Lee, J. Appl. Phys. 90, 5564 (2001). http://dx.doi.org/10.1063/ 1.1413490

[10] P. C. Becker, N. A. Olison and J. R. Simpson, Erbium doped fiber amplifiers fundamental and technology, Harcourt Brace \& Company, London, 1999.

[11] A. Polman, J. Appl. Phys. 82, 1 (1997). http://dx. doi.org/10.1063/1.366265

[12] B. Julian, R. Corberan, E. Cordoncillo, P. Esoribano, B. Viana and C. Sanchez, Nanotechnol. 16, 2707 (2005). http://dx.doi.org/10.1088/0957-4484/16/ $11 / 040$

[13] C. Falcony, A. Ortiz, M. Garcia and J. S. Helman, J. Appl. Phys. 63, 2378 (1988). http://dx.doi.org/10. 1063/1.341055
[14] A. Ortiz, C. Falcony, M. Garcia and A. Sanchez, J. Phys. D 20, 670 (1987). http://dx.doi.org/10.1088/ 0022-3727/20/5/019

[15] D. V. Voort, A. Imbof and G. J. Blasse, Solid State Chem. 96, 311 (1992). http://dx.doi.org/10.1016/ S0022-4596(05) 80264-6

[16] F. Gu, S. F. Wang, M. K. Lu, G. J. Zhou, D. Xu and D. R. Yuan, Langmuir, 20, 3528 (2004). http://dx. doi.org/10.1021/la049874f

[17] R. Garcia, G. A. Hirata and J. Mckittick, J. Mater. Res. 16, 1059 (2001). http://dx.doi.org/10.1557/ JMR. 2001.0147

[18] G. K. Williamson and W. H. Hall, Acta Metall. 1, 22 (1953). http://dx.doi.org/10.1016/ 0001-6160 (53) 90006-6

[19] K. Vanheusden, W. L. Warren, C. H. Seager, D. R. Tallant and J. A. Voigt, J. Appl. Phys. 79, 7983 (1996). http://dx.doi.org/10.1063/1.362349

[20] A. Zunger, S. Lany and S. Raebige, Physics 3, 53 (2010). http://dx.doi.org/10.1103/Physics.3.53

[21] R. Nascimento, A. J. A. de Oliveira, A. A. Correa, L. O. Bulhoes, E. C. Pereira, V. M. Souza and L. Walmsley, Phys. Rev. B 67, 144422 (2003). http://dx.doi. org/10.1103/PhysRevB.67.144422

[22] F. R. de Paula, L. Walmsley, E. C. Pereira and A. J. A. Oliveira, J. Magn. Magn. Mater. 320, e193 (2008). http://dx.doi.org/10.1016/j.jmmm.2008.02.045

[23] D. Gao, Z. Zhang, J. Fu, Y. Xu, J. Qi and D. Xue, Appl. Phys. 105, 113928 (2009).

[24] S. Deng, K. P. Loh, J. B. Yi, J. Ding, H. R. Tan, M. Lin, Y. L. Foo, M. Zheng and C. H. Sow, Appl. Phys. Lett. 93, 193111 (2009). http://dx.doi.org/ 10.1063/1.3025853

[25] O. V. Yazyev, Rep. Prog. Phys. 73, 056501 (2010). http://dx.doi.org/10.1088/0034-4885/73/ $5 / 056501$

[26] A. Sundaresan and C. N. Rao, Sol. Sta. Comm. 149, 1197 (2009). http://dx.doi.org/10.1016/j. ssc. 2009.04.028

[27] A. Sundaresan, R. Bhargavi, N. Rangarajan, U. Siddesh and C. N. Rao, Phys. Rev. B 74, 161306(R) (2006). 